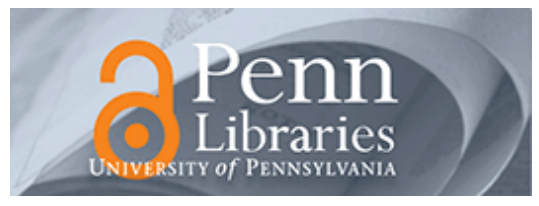

University of Pennsylvania

ScholarlyCommons

Marketing Papers

Wharton Faculty Research

$12-2008$

\title{
Beyond Conjoint Analysis: Advances in Preference Measurement
}

Oded Netzer

Olivier Toubia

Eric T. Bradlow

University of Pennsylvania

Ely Dahan

Theodoros Evgeniou

See next page for additional authors

Follow this and additional works at: https://repository.upenn.edu/marketing_papers

Part of the Marketing Commons

\section{Recommended Citation}

Netzer, O., Toubia, O., Bradlow, E. T., Dahan, E., Evgeniou, T., Feinberg, F. M., Feit, E. M., Hui, S. K., Johnson, J., Liechty, J., Orlin, J. B., \& Rao, V. R. (2008). Beyond Conjoint Analysis: Advances in Preference Measurement. Marketing Letters, 19 (3/4), 337-354. http://dx.doi.org/10.1007/s11002-008-9046-1

This paper is posted at ScholarlyCommons. https://repository.upenn.edu/marketing_papers/189

For more information, please contact repository@pobox.upenn.edu. 


\title{
Beyond Conjoint Analysis: Advances in Preference Measurement
}

\author{
Abstract \\ We identify gaps and propose several directions for future research in preference measurement. We \\ structure our argument around a framework that views preference measurement as comprising three \\ interrelated components: (1) the problem that the study is ultimately intended to address; (2) the design \\ of the preference measurement task and the data collection approach; (3) the specification and \\ estimation of a preference model, and the conversion into action. Conjoint analysis is only one special \\ case within this framework. We summarize cutting edge research and identify fruitful directions for future \\ investigations pertaining to the framework's three components and to their integration.

\section{Keywords} \\ preference measurement, conjoint analysis, marketing research \\ Disciplines \\ Business | Marketing

\section{Author(s)} \\ Oded Netzer, Olivier Toubia, Eric T. Bradlow, Ely Dahan, Theodoros Evgeniou, Fred M. Feinberg, Eleanor M. \\ Feit, Sam K. Hui, Joseph Johnson, John Liechty, James B. Orlin, and Vithala R. Rao
}




\title{
Beyond Conjoint Analysis:
}

\section{Advances in Preference Measurement ${ }^{1}$}

\author{
Oded Netzer \\ Olivier Toubia \\ Eric T. Bradlow \\ Ely Dahan \\ Theodoros Evgeniou \\ Fred M. Feinberg \\ Eleanor M. Feit \\ Sam K. Hui \\ Joseph Johnson \\ John C. Liechty \\ James B. Orlin \\ Vithala R. Rao
}

${ }^{1}$ The authors would like to thank the SEI Center for Advanced Studies in Management at Wharton for partially supporting this research and for supporting the $7^{\text {th }}$ Triennial Choice Conference held at the Wharton School. The first two authors (session co-chairs) and the third to twelfth authors are listed alphabetically. 


\begin{abstract}
We identify gaps and propose several directions for future research in preference measurement. We structure our argument around a framework that views preference measurement as comprising three inter-related components: 1) the problem that the study is ultimately intended to address; 2) the design of the preference measurement task and the data collection approach; 3) the specification and estimation of a preference model, and the conversion into action. Conjoint analysis is only one special case within this framework. We summarize cutting edge research and identify fruitful directions for future investigations pertaining to the framework's three components and to their integration.
\end{abstract}

\title{
1. Introduction: Beyond Conjoint Analysis
}

Researchers and practitioners often equate preference measurement with conjoint analysis. Indeed, since its introduction (Green and Rao 1971), conjoint analysis (and its variants) has become the method of choice for quantitative preference measurement, and is considered among the major contributions of marketing science to marketing practice. However, conjoint analysis is only a special case of the broader field of preference measurement (Gustafsson, Hermann, and Huber 2007). While academic research in conjoint analysis may be viewed by some as mature, the field of preference measurement remains very active, important, and growing.

In this paper we review recent developments in preference measurement that go beyond the "traditional" set of tools that are familiar to many practitioners and academics, and offer directions for future research. We propose viewing preference measurement as comprising three main components (see Figure 1): 1) the problem that the study is ultimately intended to address; 2) the design of the preference measurement task and the data collection approach; 3) the specification and estimation of a preference model, and the conversion into action. In the context of conjoint analysis, these three components typically take the following form: 1) the problem is to help (profit-maximizing) firms design products and/or predict market shares; 2) data collection involves consumers rating, ranking or choosing among hypothetical profiles designed according 
to traditional statistical efficiency measures; and 3) the output consists of individual-level partworths estimated assuming additive and normative utility model specifications.

\section{Figure 1: The changing landscape of preference measurement}

\begin{tabular}{|cc|}
\hline From... & to... \\
\hline helping profit-maximizing firms & $\begin{array}{c}\text { helping consumers, policy makers } \\
\text { and academics in new fields }\end{array}$ \\
\hline $\begin{array}{c}\text { designing products and } \\
\text { predicting market shares }\end{array}$ & $\begin{array}{c}\text { helping consumers make better } \\
\text { decisions and increasing social } \\
\text { welfare }\end{array}$ \\
\hline
\end{tabular}

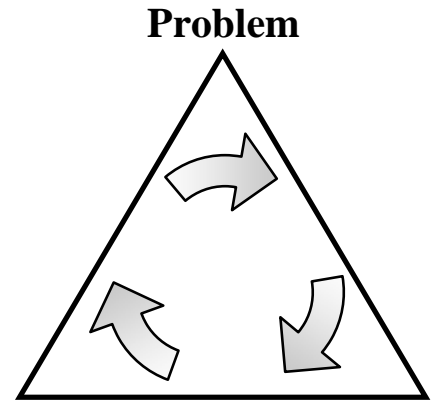

Design and Data Collection

\begin{tabular}{|cc|}
\hline From... & to... \\
\hline $\begin{array}{c}\text { traditional design efficiency } \\
\text { measures }\end{array}$ & $\begin{array}{c}\text { incorporating the problem and } \\
\text { its context into the design }\end{array}$ \\
\hline $\begin{array}{c}\text { ratings, ranking, choices of } \\
\text { hypothetical profiles }\end{array}$ & $\begin{array}{c}\text { new forms of interactions that } \\
\text { engage and entice respondents }\end{array}$ \\
\hline $\begin{array}{c}\text { relying only on stated } \\
\text { preferences }\end{array}$ & $\begin{array}{c}\text { combining stated preferences } \\
\text { with auxiliary data }\end{array}$ \\
\hline
\end{tabular}

Model Specification, Estimation, and Action

\begin{tabular}{|cc|}
\hline From... & to... \\
\hline $\begin{array}{c}\text { normative, additive and } \\
\text { stable utility functions }\end{array}$ & $\begin{array}{c}\text { modeling context dependent, non- } \\
\text { compensatory and dynamic preferences }\end{array}$ \\
\hline attributes & meta-attributes \\
\hline $\begin{array}{c}\text { using preference data to } \\
\text { estimate partworths }\end{array}$ & solving the stakeholder's problem \\
\hline
\end{tabular}

In the past few decades, many of the advances in the area of preference measurement have revolved around proposing better methods for designing conjoint analysis questionnaires and estimating individual-level partworths using relatively sparse data. However, in recent years, preference measurement researchers have contributed to all three components of the proposed preference measurement framework. Users of preference measurement studies now include, in addition to firms, consumers (e.g., using recommendation agents), policy makers, and researchers from various fields. Accordingly, the problems being addressed extend well beyond opportunistic profit maximization to altruistic consumer and social welfare objectives.

Researchers have developed novel data collection methods based on interactions between consumers and firms as well as among consumers, making the preference measurement task more engaging and appealing. In addition, incentive-compatible mechanisms have substantially improved the quality of preference measurement data. As a field, we are moving towards better, 
faster, easier to collect and truer data. Finally, researchers have started incorporating behavioral context effects, non-compensatory processes, and dynamic effects into preference models.

We hope to see more research in the future that will continue to investigate alternatives to traditional conjoint analysis along the three components of our proposed framework. Moreover, we believe that these three components are interrelated, and that the optimal decisions in each component are influenced by the other components. For example, the problem being addressed by the preference measurement study should be taken into account in all stages of the study, from the design of the task through model estimation, to the conversion of the estimated preferences into action.

\section{Problem}

The types of problems being addressed by preference measurement studies are evolving. Companies have started using preference measurement in new ways that go beyond partworth estimation, and users increasingly include consumers, policy makers and health care professionals, as well as academic researchers from fields where preference measurement is less ubiquitous.

\section{Helping companies}

Conjoint analysis has helped a large number of companies make decisions in areas such as new product development, pricing, segmentation, positioning, and advertising (Cattin and Wittink 1982, Wittink and Cattin 1989). Such decisions have relied primarily on the estimation of partworths. Given the growing diversity and complexity of the shopping environment, companies are increasingly interested in modeling and understanding the actual process through which consumers choose products, in addition to consumers' partworths. For example, Erdem, Keane, Oncu and Strebel (2005) estimated a choice model that captures the role of active information search and learning in consumer decision making in the context of high-involvement consumer durables. Iyengar, Jedidi and Kohli (2007) built a structural model of consumer preferences for non-linear contracts (e.g., two or three-part tariff cell phone plans). Gilbride and Allenby (2004) and Jedidi and Kohli (2005) went beyond partworth estimation and utilized preference measurement techniques to study the formation of consideration sets. Preference 
measurement could also be used more extensively by companies to guide project selection and investment decisions.

\section{Helping consumers}

The last few years have seen a great increase in the number of preference measurement methods designed to help consumers make better choices. The most prevalent example is that of recommendation agents. Recommenders have been and continue to be a popular research topic in various fields, such as Information Systems, Computer Science and Machine Learning (Adomavicius and Tuzhilin 2005; Srebro, Rennie and Jaakkola 2005), Psychology (Häubl and Murray 2003) and Marketing (Ansari, Essegaier and Kohli 2000; Arora et al. 2008; Häubl and Trifts 2000; Liechty, Ramaswamy and Cohen 2001; Ying, Feinberg and Wedel 2006). A good example of the revived interest in this topic is the "Netflix Prize" (www.netflixprize.com). The use of preference measurement methods in recommendation systems requires researchers to modify current methodologies in ways that substantially shorten the preference measurement task, and, in some cases, allow practitioners to estimate and utilize partworths in real-time (De Bruyn, Liechty, Huizingh and Lilien 2007).

\section{Helping policy makers and health care professionals}

Policy makers and health care professionals (e.g., doctors, drug companies, hospitals) have become increasingly interested in preference measurement techniques. Their objective may be opportunistic (e.g., maximize profit, maximize chances of winning an election) or altruistic. For example, in Medical Decision Analysis, Bleichrodt and Pinto (2000) developed a nonparametric method to elicit the probability weighting function in the context of choices between medical treatments. Saigal, Dahan and Cumberland (2007) used conjoint analysis to optimize treatment for prostate cancer based on each patient's unique tradeoffs between various outcomes and side effects.

\section{Helping academic researchers}

Preference measurement is inherently an interdisciplinary field. For example, some of its origins may be traced back to Mathematical Psychology and Transportation. While most of the active work on the topic is currently linked to Marketing, we expect the preference measurement 
community to expand to new fields in the coming years. For example, behavioral economists are increasingly interested in individual-level estimates of the parameters of the value function and the probability weighting function (Kahneman and Tversky 1979; Prelec 1998; Gonzalez and Wu 1999), in the context of cumulative prospect theory (Tversky and Kahneman 1992). Such estimates allow studying the relationship among parameters that represent loss aversion or risk aversion and individual characteristics such as age, income, or education (Tanaka, Camerer and Nguyen 2007), or between such parameters and behavior (Fehr and Goette 2007; Jarnebrant, Toubia, Johnson 2007). We believe that advances in preference measurement, such as adaptive questionnaire design and Bayesian estimation, may be very useful to this community of researchers. Similarly, researchers in preference measurement may greatly benefit from collaborating with colleagues in fields such as Computer Science (e.g., Evgeniou, Boussios and Zacharia 2005), Education (Bradlow 2005), Engineering (Michalek, Feinberg and Papalambros 2005), and Psychology (Otter, Allenby and van Zandt 2007).

\section{Design and Data Collection}

\section{Optimal experimental design: beyond A-efficiency and D-efficiency}

The design of conjoint experiments has traditionally focused on maximizing design efficiency measures such as D-efficiency or A-efficiency (Addelman 1962; Kuhfeld, Tobias and Garratt 1994). These measures of efficiency are based on matrix norms defined on the covariance matrix of the estimates of the partworths. In other words, in the context of an individual-level regression, D-efficient or A-efficient designs (such as the well known orthogonal designs) produce partworth estimates that have minimal variance and intercorrelation.

However, those traditional efficiency measures overlook the managerial objective of the preference measurement study. In particular, while traditional measures of efficiency focus on the covariance matrix of the partworths, managers typically take actions that are based on some functions of these partworths (e.g., willingness to pay for a specific feature), and put more weight on some decisions than others. Toubia and Hauser (2007) proposed M-efficiency measures that account for such managerial considerations. Future research may incorporate other aspects of the environment, such as engineering constraints (Michalek, Feinberg and Papalambros 2005) or prior knowledge of consumers’ preferences, into the design stage of 
preference measurement studies. For example, Gensler, Theysohn, Hinz and Skiera (2007), consider for each individual the acceptable range of willingness to pay for each feature in the design of an adaptive choice-based conjoint analysis. Along similar lines, the existence of unacceptable product features or combinations of features may have an impact on the criteria used to evaluate possible designs. Note, however, that one should be cautious in asking consumers directly which attribute levels are unacceptable (Green, Krieger and Bansal 1988).

More generally, we believe that experimental design may be greatly enhanced via a systematic approach using Bayesian Decision Theory (Chaloner and Verdinelli 1995). Bayesian experimental designs minimize an expected loss function over the posterior distribution of the parameter estimates. For example, Sandor and Wedel (2001) proposed a method for eliciting managers’ prior beliefs about attribute preferences and used this prior information to design Bayesian D-efficient choice experiments. Sandor and Wedel (2005) showed how taking prior information about heterogeneity across consumer preferences into account affects design optimality. In particular, they show how the use of a small set of different conjoint designs improves efficiency over a single design administered to all participants. However, A-efficiency and D-efficiency are just special cases corresponding to two particular loss functions. The specific context of the study may give rise to alternative loss functions and/or prior distributions on the parameters that more accurately reflect the objectives and beliefs of the user. In sum, when designing a preference measurement task, we encourage researchers to incorporate aspects such as managerial objectives, prior beliefs, constraints and characteristics of the task, into the criteria used to evaluate the design.

\section{New Forms of Interactions}

Traditionally, preference measurement data have been collected using pencil and paper questionnaires or one-on-one or mail-telephone-mail interviews involving sorting or rating tasks. Since the early 90's, many respondent interactions have been relegated to computer and web interfaces. The use of web-based questionnaires triggered the development of adaptive methods that allow collecting more information per question. Adaptive methods include the commercially available Adaptive Conjoint Analysis (ACA, Johnson 1987), the Fast Polyhedral approach (Toubia et al. 2003; Toubia, Hauser and Garcia, 2007; Toubia, Hauser and Simester 2004; Vadali, 
Liechty and Rangaswamy 2007), the Adaptive Self-Explicated approach (Netzer and Srinivasan 2007).

However, the technological advances and easier accessibility to respondents afforded by the web come at the cost of decreased respondent patience and attentiveness. Thus, it is becoming more important than ever to keep respondents engaged with the task. Dahan and Hauser (2002) surveyed several virtual interactive web-based interfaces that have been proposed in the past few years to address that issue. For example, the user design approach collects preference data by allowing respondents to design their ideal virtual product (von Hippel and Katz 2002). The Information Pump (Prelec 2001) and the Securities Trading of Concepts (STOC; Dahan, Lo, Poggio, Chan and Kim 2007 and Dahan, Soukhoroukova and Spann 2007) collects preference data by allowing respondents to interact with one another in game-like mechanisms, making the task more engaging and fun. Note that, when designing data collection methods that are based on interactions among consumers, one needs to be aware of biases that such interactions may induce (Johnson, Tellis and MaCinnis 2005). Keeping respondents engaged may also be achieved by showing them physical prototypes to increase the realism of the task (Luo, Kannan and Ratchford 2007; Srinivasan, Lovejoy and Beach 1997). Dahan and Srinivasan (2000) took this approach even further and reduced its cost by developing a web interface to measure preferences using static or dynamic virtual prototypes.

Another method to increase consumer involvement is to replace the commonly used hypothetical data collection exercises with incentive-aligned tasks, in which respondents have to “live with” their decisions (Ding 2007; Ding, Grewal and Liechty 2005; Park, Ding and Rao 2007; Prelec 2001). A recent study by Ding (2007) suggested that incentive-aligned mechanisms may be used even when not all the product profiles exist in the market. Incentive-aligned mechanisms were empirically found to increase not only respondents’ engagement but also outof sample predictive validity. For example, the incentive-aligned mechanism proposed by Ding, Grewal and Liechty (2005) increased hit rates (correct prediction of the first choice out of 21 options) by almost a factor of two (from $26 \%$ to $48 \%$ ). Incentive-aligned mechanisms have been also shown to be very effective in economic experiments for market design such as matching and public goods problems (Amaldoss et al. 2008).

In summary, when building a data collection mechanism, it is important to keep in mind the experience of the consumer completing the task. Specifically, since the ultimate goal is 
usually to predict actual behavior, engaging and incentive-compatible mechanisms should be favored over hypothetical tasks.

\section{Dealing with Large Number of Attributes and Products}

As products become more complex, consumer preferences need to be measured over a larger number of product attributes and levels. Applications of conjoint analysis have been conducted on products involving as many as fifty product attributes (Wind et al. 1989). Several methods have been proposed to handle the demand for complex problems. The traditional selfexplicated approach (Srinivasan 1988) can deal with a large number of attributes and levels. However, this approach carries several limitations (Green and Srinivasan 1990), which have been partially overcome by hybrid estimation methods that combine self-explicated data with preference data from full or partial profile tasks (Green, Goldberg and Montemayor 1981; Johnson 1987; Marshall and Bradlow 2002; ter Hofstede, Kim and Wedel 2002). Utilizing the concept of complexity control from machine learning, Cui and Curry (2005) and Evgeniou, Boussios and Zacharia (2005) used a support vector machine approach to handle complex preference measurement problems.

Recently, researchers have proposed to address the problem of large product dimensionality by developing innovative data collection mechanisms. For example, the Conjoint Adaptive Ranking Database System (CARDS) method proposed by Dahan (2007) simplifies the conjoint analysis task by asking respondents to choose only among the very limited number of sets that are perfectly mapped to specific utility functions proposed in advance by the researcher. Park, Ming and Rao (2007) proposed an auction-based approach in which respondents can auction a large number of product feature upgrades. Taking a different approach, Netzer and Srinivasan (2007) developed an adaptive self-explicated approach to solve the self-explicated constant sum question problem when the number of product attributes becomes large, demonstrating significant improvement in predictive validity. We expect that many of the advances in our ability to study complex problems will come from the development of such innovative data collection techniques and from the use of auxiliary information. 


\section{Combining Multiple Sources of Data}

Traditionally, preference measurement studies have relied on data provided explicitly and consciously by consumers during the preference measurement task. Recently, marketers have started identifying new sources of data and supplementing stated preference data with auxiliary revealed preference data, in order to 1) improve predictive ability; 2) ask fewer questions; 3) correct biases related to the preference measurement task. ${ }^{2}$ Such auxiliary data may be either internal or external to the preference measurement task.

\section{Internal sources of data}

Examples of data that are internal to the task include response latencies, eye movement and mouse movement. Haaijer, Kamakura and Wedel (2000) demonstrated that response time is related to preference by means of choice uncertainty, whereby shorter response times represent more certain choices. Otter, Allenby and van Zandt (2007) proposed a Poisson race model to capture response time in conjoint analysis. Netzer, Schrift and Toubia (2007) modeled and exploited the relation between response time and choice conflict. Liechty, Pieters and Wedel (2003) utilized eye movement data to identify the attention state of respondents when evaluating stimuli. In the future, we expect that more decision process data such as mouse movement, clickstream data and brain images will be utilized in preference measurement.

\section{External sources of data}

Examples of auxiliary data that are external to the task include, but are not limited to, sales and market share data. Feit, Beltramo and Feinberg (2007) developed a method for melding experimental choice data and data on market purchases to leverage the best properties of both. Along the same lines, Horsky, Misra and Nelson (2006) demonstrated the benefits of combining scanner-based data with survey-based preference data. Gilbride, Lenk and Brazell (2006) proposed a loss function approach to incorporate market share information as constraints in the estimation of choice-based conjoint analysis partworths. De Bruyn, Liechty, Huizingh and Lilien (2007) combined preference measurement data with intended product use and customer characteristics data, in the context of recommendation agents. Some less traditional sources of auxiliary data have also been investigated recently. For example, Hui, Bradlow and Fader (2007)

\footnotetext{
${ }^{2}$ We refer the reader to the previous Choice Symposium papers by Ben Akiva et al. (1994) and Louviere et al. (1999) for a summary of the benefits and difficulties of combining stated and revealed preference data.
} 
and Hui, Fader and Bradlow (2007) measured consumer preferences by combining shopping path data (collected using RFID technology) with transaction data. Another promising external source of data includes readily available data posted on the internet, such as product reviews (Lee and Bradlow 2007).

With the advantages offered by combining multiple sources of information comes the difficulty and complexity of combining data sets that are often not fully aligned with one another. Several approaches have been suggested including data fusion (Gilula, McCulloch and Rossi 2006), common individual characteristics (Feit, Beltramo and Feinberg 2007) and common latent constructs underlying the multiple data sets (Hui, Bradlow and Fader 2007).

We encourage researchers to identify unique sources of data that could improve our ability to measure consumers' preferences and to develop methods to overcome the difficulties involved in combining multiple sources of data.

\section{Model Specification, Estimation, and Action Taking Social interactions into account}

Preference measurement models have almost exclusively assumed that consumers make choices independently of one another. Some noteworthy exceptions include Rao and Steckel (1991) who studied the polarizing effects of group decision making, Arora and Allenby (1999) who modeled decisions made jointly by husbands and wives, and Ding and Eliashberg (2007) who proposed formal models of multi-party decision-making and applied them to choices of pharmaceutical prescriptions by doctors and patients. Recent research in marketing has continued to highlight and illustrate the importance of social interactions in consumption and choices (e.g., Godes and Mayzlin 2004; Goldenberg, Libai and Muller 2002). We believe that capturing such interactions more systematically in preference measurement is an important area for future research.

\section{Meta-attributes}

Preferences are often modeled and estimated in the space defined by product attributes and levels. Working in this space makes the translation of consumer preferences into engineering terms easier. However, consumers often think in terms of "meta-attributes" such as needs, motivations and goals, which may correspond to bundles of physical product attributes. There 
are several advantages to working in meta-attribute spaces. First, if consumers indeed evaluate products according to meta-attributes, the preference measurement task may become more natural. Second, using dimensions like goals and needs, which are the true drivers of decision making, is likely to lead to better preference measurement. Finally, needs, motivation and goals are likely to be more stable over time than preferences for specific product attributes (e.g., consumers may have stable preference for faster computers, but their preference for a specific processor may change over time as technology evolves). While working with meta-attributes may be beneficial, identifying and constructing meta-attributes can prove to be difficult. Methods such as Factor Analysis may give some insights, but lack the fundamental ability to create maps between physical attributes and meta-attributes. The challenge of finding these maps is confounded with issues of language that could be used to describe meta-attributes. Text mining of consumer-written product reviews (Lee and Bradlow 2007) is a potentially valuable tool for automating the process of identifying the language consumers use to describe products. Furthermore, the translation between meta-attributes defined in consumer language and engineering specifications used in product design may not be straightforward.

Luo, Kannan and Ratchford (2007) incorporated “meta-attributes such as “comfort” and “power” along with more objective characteristics. In the context of recommendation agents, De Bruyn, Liechty, Huizingh and Lilien (2007) used tree-based methods combined with higher level “ask-once” questions to group consumers, suggesting that meta-attributes may be related to and identified with “ask-once” questions in online or offline recommendations. Ghose and Rao (2007) tackled directly the topic of how one could construct and utilize meta-attributes in the context of conjoint analysis. We hope to see more work along these lines in the future.

\section{More flexible utility functions}

Preference measurement has typically assumed linear and additive utility functions. An increasing number of papers have explored utility functions that deviate from these assumptions. For example, Kim, Menzefricke and Feinberg (2007) modeled preferences using Bayesian splines with endogenous knot configurations, finding hold-out choice prediction improvement in the $10-20 \%$ range. Ben-Akiva et al. (2002) proposed a hybrid choice model that integrates many types of discrete choice modeling methods, draws on different types of data, and allows the explicit modeling of latent psychological explanatory variables. Other researchers have explored 
non-compensatory utility functions. Yee, Dahan, Hauser and Orlin (2007) and Kohli and Jedidi (2007) proposed dynamic programming methods to estimate lexicographic preference structures. Non-compensatory processes seem particularly relevant in the context of consideration sets. Gilbride and Allenby (2004) modeled a two stage process in which the first stage consists of a (potentially) non-compensatory screening of alternatives and the second stage of a compensatory choice among the remaining alternatives. They estimated their model using hierarchical Bayes methods, augmenting the latent consideration sets within their MCMC approach. Jedidi and Kohli (2005) introduced subset-conjunctive screening rules, which generalize disjunctive and conjunctive rules. Non-compensatory decision process may be viewed as the result of simplifying heuristics used by boundedly rational consumers during the preference measurement task. For example, Kim (2004) used a Bayesian hidden Markov model to describe changes in individual consumers’ latent choice heuristics over time.

We hope that future work in this area will enhance the ecological rationality of preference measurement models, i.e., will improve the fit between the structural properties of the model and the structure of the environment to which it is applied.

\section{Incorporating behavioral effects}

The process of data collection in preference measurement often involves a sequence of choices, ranking, ratings, or tradeoffs between attributes and/or products. Much of the research in Behavioral Decision Theory has been focused on studying context and other behavioral effects that may be prevalent when consumers are making such decisions. Therefore, it is surprising that only a handful of studies have attempted to test and apply the battery of robust and significant behavioral effects documented in the consumer behavior literature to preference measurement.

Some of the early work on incorporating behavioral effects into preference measurement explored the effect of the number of attribute levels on the perceived attribute importances (Wittink, Krishnamurthi and Reibstein 1989). The authors suggested that researchers should try to keep the number of attribute levels similar across attributes, in order to avoid biases. Bradlow, Hu and Ho (2004) investigated and modeled the behavioral effects caused by omitting product attributes in partial profile designs. A few studies have also attempted to model context effects in preference measurement. Kivetz, Netzer and Srinivasan (2004a) proposed several choice models that could capture the well-known compromise effects given a set of partworths collected using 
alternative preference measurement tasks. In a follow-up paper, the authors suggested that their models could capture additional context effects such as asymmetric dominance, attraction and detraction (Kivetz, Netzer and Srinivasan 2004b). Haaijer, Wedel, Vriens and Wansbeek (1998) proposed a flexible covariance matrix that could potentially capture context effects in choicebased conjoint analysis. The paper by Adamowicz et al. (2008), appearing in the current issue of the journal, provides a detailed overview of behavioral effects in choice modeling.

One of the difficulties involved with studying behavioral issues in preference measurement is that one cannot claim that a model describes behavior better than another model based on superior fit or predictive ability only. In particular, more complex models naturally tend to fit better and can often predict worse (due to potential overfitting). Therefore, many factors may influence fit and predictive ability, beyond the accuracy of the behavioral assumptions made by the model. Claiming that a model is isomorphic to the true underlying decision process (i.e., it actually captures the underlying behavior) seems to require exogenous manipulations and/or a set of process measures. Otherwise, a model may only be shown to be paramorphic to the true underlying decision process (i.e., it gives rise to similar outcomes).

Nevertheless, we believe that with the increase in the number of contact points between firms and consumers, and therefore in the number of ways in which practitioners may influence the choice process, consumer psychology is more relevant than ever to preference measurement from a managerial perspective. From an academic perspective, we hope to see a two-way exchange between the preference measurement and consumer psychology literatures. Psychologists can suggest behavioral effects that may improve the accuracy of preference measurement while preference researchers in turn can develop new methods for measuring and testing alternative behavioral effects.

\section{Modeling learning, dynamics and preference formation}

Most preference measurement models assume that consumers have well-defined and stable preferences. The above discussion suggests that preferences may not be well-formed and may be influenced by the task itself and by its context. Furthermore, if preferences are not wellformed we are likely to observe dynamics throughout the preference measurement task as a result of preference formation, learning or fatigue. DeSarbo, Fong, Liechty and Coupland (2005) and Liechty, Fong and DeSarbo (2005) proposed models that allow the partworth estimates to 
vary throughout the preference measurement task using a dynamic random effects model. Su and Rao (2007) studied the evolution of willingness to pay for different types of attributes and how such changes affect new product adoption. Many of the flexible models developed to capture dynamics in repeated choice (e.g., Kim, Menzefricke and Feinberg 2005; Lachaab, Ansari, Jedidi and Trabelsi 2006) could be applied to preference measurement. Bradlow, Hu and Ho (2004) take a first step in understanding the antecedents of dynamics by studying consumer learning about preferences for missing attribute levels in a partial profile design. We join Bradlow (2005) in the call for more work attempting to disentangle the different sources of dynamic effects in preference measurement.

\section{Recent tools for estimation}

The standard estimation method for conjoint analysis has become hierarchical Bayes (Lenk et al. 1996; Rossi and Allenby 2003). Although this estimation method has been researched extensively, it continues to be an exciting research area. For example, Sonnier, Ainslie and Otter (2007) showed that specifying a normal heterogeneity distribution on the parameters of the multinomial logit model implies a distribution on willingness-to-pay that has substantial mass in the tail, leading to extreme behavior for some individuals. This suggests that priors or heterogeneity distributions should be specified on meaningful quantities (e.g., willingness-to-pay) instead of on latent constructs, like partworths.

An alternative approach to conjoint estimation is based on optimization. This approach has a long history, starting with the Linmap method of Srinivasan and Shocker (1973a, 1973b). More recently, Toubia et al. (2003) and Toubia, Hauser and Simester (2004) proposed polyhedral methods for conjoint estimation and questionnaire designs. These methods are based on interpreting the answer to each conjoint question as a constraint on the respondent's partworths. Toubia, Hauser and Garcia (2007) and Vadali, Liechty and Rangaswamy (2007) generalized the polyhedral methods to capture response error and informative priors on the parameters. Evgeniou, Boussios and Zacharia (2005), Cui and Curry (2005) and Evgeniou, Pontil and Toubia (2007) proposed conjoint estimation methods based on machine learning and statistical learning theory. The method of Evgeniou, Pontil and Toubia (2007) has been shown to outperform, in some cases, hierarchical Bayes in estimation accuracy and predictive ability. The two methods are comparable conceptually, with the fundamental difference that all parameters are endogenous in 
the machine learning method of Evgeniou, Pontil and Toubia (2007) while some parameters are typically set exogenously in hierarchical Bayes (e.g., the hyperparameters). Finally, Toubia, Evgeniou and Hauser (2007) showed that many optimization methods for conjoint estimation may be integrated within the framework of statistical learning theory.

One of the current limitations of optimization-based methods is that they produce point estimates, whereas likelihood-based methods such as hierarchical Bayes provide full distributions on the parameter estimates. While Evgeniou, Pontil and Toubia (2007) illustrated a bootstrapping approach to obtaining confidence intervals for their method, we believe that future research may explore alternative approaches to allow statistical inference and hypothesis testing for optimization-based methods. More generally, a fundamental challenge that we hope will be addressed in future research is linking optimization-based methods with likelihood-based methods. For example, Toubia, Hauser and Garcia (2007) and Vadali, Liechty and Rangaswamy (2007) gave a likelihood interpretation of polyhedral methods. Bridging the likelihood-based and optimization-based approaches may benefit both approaches. For example, Evgeniou, Pontil and Toubia (2007) showed an example of how principles from statistical learning theory may be used to significantly improve the estimation accuracy and predictive ability of hierarchical Bayes estimation.

\section{From model to action}

Parameter estimation is often thought of as the final stage of a preference measurement study. However, at the conclusion of a study, it is imperative to come back to the original problem that motivated the study and ensure that a solution is provided to that problem. Some of the key decisions in marketing are those of optimal product design and product line optimization (Dobson and Kalish 1993; Green and Krieger 1985; Kohli and Sukumar 1990; McBride and Zufryden 1988). Recently, Luo, Kannan, Besharati and Azarm (2005) proposed an approach that takes into account variations in the conditions under which the product will be used, and introduced the concept of "robust product design," which offers excellent performance under worst-case variations and low sensitivity to variations. Recent models in the area of product line optimization have also emerged from engineering, using detailed physical models to determine which products can be produced (Michalek, Feinberg and Papalambros 2005; Wassenaar et al. 2005). These models combine innovate ways to define feasibility constraints with tailored 
optimization algorithms. For example, Michalek et al. (2007) used Analytical Target Cascading (ATC) to formally coordinate models from marketing and engineering, and design "optimal” marketing-based products and product lines that are technically feasible.

Beyond product line optimization, we believe that the managerial relevance and impact of preference measurement studies may be enhanced by systematically modeling the Bayesian decision theoretic loss function of the stakeholder (company, consumers, policy makers, etc.), and providing decision support tools for identifying the action that will minimize this loss function over the entire posterior distribution of the parameters being estimated. Currently, most preference measurement studies are used to produce point estimates of some parameters, such as partworths. However, basing decisions on point estimates is suboptimal, as decisions should be based on the expected loss across the entire posterior distribution of the estimates (Chaloner and Verdinelli 1995). For example, Blattberg and George (1992) showed that incorporating the manufacturer's goal of profit-maximizing into the Bayesian loss function leads to smaller pricesensitivity estimates and higher optimal prices. Note that in some of the new domains of application identified earlier in this paper, the loss function may take very different forms from that of a profit-maximizing firm. For example, the appropriate loss function for a recommendation agent may include both the utility derived by the consumer from the recommended product and the effort spent by the consumer throughout his or her interactions with the agent. Given the fact that Bayesian Decision Theory involves integrating over posterior distributions, we believe that there is an opportunity to construct decision support tools that will simplify the choice of actions, based on the output of the preference measurement study and all other relevant information.

\section{In Conclusion..."Every Generation Needs a New Revolution"3}

Preference measurement is a very exciting and active field that goes well beyond conjoint analysis. We proposed a framework, consisting of three inter-related components, for approaching this field. We have summarized some cutting edge research and identified fruitful directions for future research pertaining to the framework’s three components, and to their

\footnotetext{
3 Thomas Jefferson.
} 
mutual integration. The past two decades have seen great advances in conjoint analysis through the use of computerized adaptive questionnaires and the development of new estimation methods that account for consumer heterogeneity. Moving forward, we encourage researchers to go beyond conjoint analysis and explore new problems and applications of preference measurement, develop new forms of data collection that engage and entice respondents, take advantage of the availability of new sources of data, model new phenomena such as behavioral effects and dynamics, and combine statistical and optimization methods to improve estimation. Moreover, we encourage researchers to take into account the objectives and context of the preference measurement study throughout each step of the process. 


\section{References}

Adamowicz, Wictor, David Bunch, Trudy-Anne Cameron, Benedict G.C. Dellaert, Michael Hanneman, Michael Keane, Jordan Louviere, Robert Meyer, Thomas Steenburgh, Joffre Swait (2008), "Behavioral Frontiers in Choice Modeling," Marketing Letters, forthcoming.

Addelman, Sidney (1962), "Symmetrical and Asymmetrical Fractional Factorial Plans,” Technometrics, 4 (February) 47-58.

Adomavicius, Gediminas and Alexander Tuzhilin (2005), “Toward the next generation of recommender systems: a survey of the state-of-the-art and possible extensions," IEEE Transactions on Knowledge and Data Engineering, 15 (6), 734-749.

Amaldoss, Wilfred, Teck-Hua Ho, Aradhna Krishna, Kay-Yut Chen, Preyas Desai, Ganesh Iyer, Sanjay Jain, Noah Lim, John Morgan, Ryan Oprea, and Joydeep Srivasatava (2008), “Experiments on Strategic Choices and Markets,” Marketing Letters, forthcoming.

Ansari, Asim, Skander Essegaier, and Rajeev Kohli (2000), “Internet Recommendation Systems,” Journal of Marketing Research, 37 (August), 363-375.

Arora, Neeraj and Greg Allenby (1999), "Measuring the Influence of Individual Preference Structures in Group Decision Making,” Journal of Marketing Research, 36 (4), 476-487.

Arora, Neeraj, Anindya Ghose, James D. Hess, Raghuram Iyengar, Bing Jing, Yogesh Joshi, V. Kumar, Nicholas Lurie, Scott Neslin, S. Sajeesh, Meng Su, Niladri Syam, Jacquelyn Thomas, Z. John Zhang (2008), "Putting One-to-One Marketing to Work: Personalization, Customization and Choice,” Marketing Letters, forthcoming.

Ben-Akiva, Moshe, M. Bradley, T. Morikawa, J. Benjamin, Thomas P. Novak, P. Thomas, Harmen Oppewal and Vithala Rao (1994), “Combining Revealed and Stated Preference Data,” Marketing Letters, 5 (4), 335-350.

Ben-Akiva, Moshe, Daniel McFadden, Kenneth Train, Joan Walker, Chandra Bhat, Michel Bierlaire, Denis Bolduc, Axel Boersch-Supan, David Brownstone, David S. Bunch, Andrew Daly, Andre De Palma, Dinesh Gopinath, Anders Karlstrom and Marcela A. Munizaga (2002), "Hybrid Choice Models, Progress and Challenges,” Marketing Letters, 13 (3), 163-175.

Blattberg, Robert C., and Edward I. George (1992), "Estimation Under Profit-Driven Loss Functions,” Journal of Business and Economic Statistics, 437-444.

Bleichrodt, Han, and Jose Luis Pinto (2000), “A Parameter-Free Elicitation of the Probability Weighting Function in Medical Decision Analysis,” Management Science, 2000, 46 (11), 1485-1496.

Bradlow, Eric T. (2005), “Current Issues and a Wish-List for Conjoint Analysis,” Applied Stochastic Models in Business and Industry, (4-5), 319-323.

Bradlow, Eric T., Ye Hu and Teck-Hua Ho (2004), “A Learning-Based Model for Imputing Missing Levels in Partial Conjoint Profiles,” Journal of Marketing Research, 41(4), 369-381.

Cattin, Philippe, and Dick R. Wittink, “Commercial Use of Conjoint Analysis: A Survey,” Journal of Marketing, 46 (3). 44-53.

Chaloner, Kathryn and Isabella Verdinelli (1995), “Bayesian Experimental Design: A Review,” Statistical Science, 10(3), 273-304.

Cui, Dapeng, and David Curry (2005), “Prediction in Marketing Using the Support Vector Machine,” Marketing Science, 24 (4), 595-615.

Dahan, Ely (2007), “Conjoint Adaptive Ranking Database System,” working paper, University of California at Los Angeles.

Dahan, Ely and John R. Hauser (2002), “The Virtual Customer,” Journal of Product Innovation Management, 19, 332-353. 
Dahan, Ely, Andrew Lo, Tomaso Poggio, Nicholas Chan and Adlar Kim (2007), "Securities Trading of Concepts (STOC),” working paper, University of California at Los Angeles.

Dahan, Ely, Arina Soukhoroukova and Martin Spann (2007) "Preference Markets: Organizing Securities Markets for Opinion Surveys with Infinite Scalability,” working paper, University of California at Los Angeles.

Dahan, Ely, and V. Srinivasan (2000), “The Predictive Power of Internet-Based Product Concept Testing Using Visual Depiction and Animation” Journal of Product Innovation Management, March, 99-109.

De Bruyn, Arnaud, John C. Liechty, Eelko K.R.E. Huizingh and Gary L. Lilien (2007), "Offering Online Recommendations with Minimum Customer Input through Conjoint-Based Decision Aids," Marketing Science, forthcoming.

DeSarbo, Wayne, Duncan K.H. Fong, John C. Liechty, and Jennifer Chang Coupland (2005), "Evolutionary Preferences/Utility Functions: A Dynamic Perspective,” Psychometrika, 70(1), 179.

Ding, Min (2007), “An Incentive-Aligned Mechanism for Conjoint Analysis,” Journal of Marketing Research, 44 (May), 214-223.

Ding, Min and Jehoshua Eliashberg (2007), “A Dynamic Competitive Forecasting Model Incorporating Dyadic Decision-Making,” forthcoming, Management Science.

Ding, Min, Rajdeep Grewal and John Liechty (2005), “Incentive-Aligned Conjoint Analysis,” Journal of Marketing Research, 42 (February), 67-82

Dobson, Gregory and Shlomo Kalish (1993), "Heuristics for Pricing and Positioning a Product-Line Using Conjoint and Cost Data," Management Science, 7 (2), 107-125.

Erdem, Tülin, Michael Keane, Sabri Öncü and Judi Strebel (2005), "Learning about Computers: An Analysis of Information Search and Technology Choice,” Quantitative Marketing and Economics, 3, (3), 207-247.

Evgeniou, Theodoros, Constantinos Boussios and Giorgos Zacharia (2005), “Generalized Robust Conjoint Estimation,” Marketing Science, 24(3), 415-429.

Evgeniou, Theodoros, Massimiliano Pontil, and Olivier Toubia (2007), “A Convex Optimization Approach to Modeling Consumer Heterogeneity in Conjoint Estimation,” Marketing Science, forthcoming.

Fehr, Ernst and Lorenz Goette (2007), "Do Workers Work More if the Wages are Higher: Evidence from a Randomized Field Experiment,” The American Economic Review, 97(1), 298-317.

Feit, Eleanor M., Mark A. Beltramo and Fred M. Feinberg (2007), “Combining Survey and Market Data to Enhance Consumer Preference Models,” working paper, University of Michigan.

Gensler, Sonja, Sven Theysohn, Oliver Hinz and Bernd Skiera, "Improving Willingness-to-Pay Estimation in Choice-Based Conjoint Analysis,” working paper, Frankfurt University, Germany

Gilbride, Timothy J. and Greg M. Allenby (2004), "A Choice Model with Conjunctive, Disjunctive, and Compensatory Screening Rules,” Marketing Science, 23(3), 391-406.

Gilbride, Timothy J., Peter J. Lenk and Jeff D. Brazell (2006), "Market Share Constraints and the Loss Function in Choice Based Conjoint Analysis,” working paper, University of Notre Dame.

Gilula, Zvi, Robert E. McCulloch and Peter E. Rossi. (2004). “A Direct Approach to Data Fusion,” Journal of Marketing Research, 43 (1), 73-83

Ghose, Sanjoy and Vithala R. Rao (2007), “A Choice Model of Bundles Features and Meta-Attributes: An Application to Product Design,” working paper, Cornell University.

Godes, David, and Dina Mayzlin, “Using Online Conversations to Study Word-of-Mouth Communication,” Marketing Science, 23(4), 545-560.

Goldenberg, Jacob, Barak Libai, and Eitan Muller, "Riding the Saddle: How Cross-Market Communications Can Create a Major Slump in Sales,” Journal of Marketing, 66(2), 1-16. 
Gonzalez, Richard and George.Wu (1999), “On the Shape of the Probability Weighting Function,” Cognitive Psychology, 38, 129-166.

Green, Paul E., Stephen M. Goldberg and Mila Montemayor (1981), “A Hybrid Utility Estimation Model for Conjoint Analysis,” Journal of Marketing, 45 (Winter), 33-41.

Green, Paul E., and Abba M. Krieger (1985), "Models and Heuristics for Product Line Selection,” Marketing Science, 4(1), 1-19.

Green, Paul E. Abba M. Krieger, and Pradeep Bansal (1988), “Completely Unacceptable Levels in Conjoint Analysis: A Cautionary Note,” Journal of Marketing Research, 25 (August), 293-300.

Green, Paul E and Vithala R. Rao (1971), “Conjoint measurement for quantifying judgmental data,” Journal of Marketing Research, 8, 355-363.

Green, Paul E. and V. Srinivasan (1990), “Conjoint Analysis in Marketing: New Developments with Implications for Research and Practice,” Journal of Marketing Research, 54 (October), 3-19.

Gustafsson, Anders, Andreas Herrmann, and Frank Huber (2007), "Conjoint Measurement: Methods and Applications (fourth edition),” Springer Verlag: Berlin.

Haaijer, Marinus E. Wagner A. Kamakura and Michel Wedel (2000) "Response Latencies in the Analysis of Conjoint Choice Experiments,” Journal of Marketing Research, 37(3) 376-82.

Haaijer, Rinus, Michel Wedel, Marco Vriens, and Tom Wansbeek (1998), "Utility Covariances and Context Effects in Conjoint MNP Models,” Marketing Science, 17, 3, 236-252.

Häubl, Gerald and Kyle B. Murray (2003), "Preference Construction and Preference in Digital Marketplaces: The Role of Electronic Recommendation Agents,” Journal of Consumer Psychology, 13, 75-91.

Häubl, Gerald, and Valerie Trifts (2000), “Interactive Decision Aids,” Marketing Science, 19 (1), 4-21.

Horsky, Dan, Sanjay Misra and Paul Nelson (2006), “Observed and Unobserved Preference Heterogeneity in Brand-Choice Models,” Marketing Science, 25 (4), 322-335.

Hui, Sam K., Eric T. Bradlow and Peter S. Fader (2007), “An Integrated Model of Grocery Store Shopping Path and Purchase Behavior,” working paper, The Wharton School, University of Pennsylvania.

Hui, Sam K., Peter S. Fader and Eric T. Bradlow (2007), "Path Data in Marketing: An Integrative Framework and Prospectus for Model-Building,” working paper, The Wharton School, University of Pennsylvania.

Iyengar, Raghuram, Kamel Jedidi and Rajeev Kohli (2007), “A Conjoint Approach to Multi-Part Pricing,” working paper, Columbia Business School.

Jarnebrant, Peter, Olivier Toubia and Eric J. Johnson (2007), “The Silver Lining Effect: Formal Analysis and Experiments,” working paper, Columbia Business School.

Jedidi, Kamel and Rajeev Kohli (2005), "Probabilistic Subset-Conjunctive Models for Heterogeneous Consumers," Journal of Marketing Research, 42 (4), 483-494.

Johnson, Joseph, Gerard J. Tellis and Deborah J. MacInnis (2005), “Losers, Winners and Biased Trades," Journal of Consumer Research, 32 (2), 324-329.

Johnson, Richard M. (1987), “Adaptive Conjoint Analysis,” in: Sawtooth Software Conference Proceedings, Ketchum, ID: Sawtooth Software, July, 253-265.

Kahneman, Daniel and Amos Tversky (1979), "Prospect Theory: An Analysis of Decision Under Risk," Econometrica, 47(2), 263-292.

Kim, Jin Gyo (2004), "Dynamic Heterogeneous Choice Heuristics: A Bayesian Hidden Markov Mixture Model Approach,” Working Paper, MIT Sloan School of Management.

Kim, Jin Gyo, Ulrich Menzefricke and Fred M. Feinberg (2005), "Modeling Parametric Evolution in a Random Utility Framework,” Journal of Business and Economic Statistics, 23 (5), 282-294. 
Kim, Jin Gyo, Ulrich Menzefricke and Fred M. Feinberg (2007), "Capturing Flexible Heterogeneous Utility Curves: Bayesian Spline Approach,” Management Science, 53(2), 340-354.

Kivetz, Ran, Oded Netzer and V. Srinivasan. (2004a), “Alternative Models for Capturing the Compromise Effect,” Journal of Marketing Research, 41(3), 237-257.

Kivetz, Ran, Oded Netzer and V. Srinivasan. (2004b), "Extending Compromise Effect Models to Complex Buying Situations and Other Context Effects,” Journal of Marketing Research, 41(3), 262-268.

Kohli, Rajeev, and Kamel Jedidi (2007), "Representation and Inference of Lexicographic Preference Models and Their Variants,” Marketing Science, 26(3), 380-399.

Kohli, Rajeev and R. Sukumar (1990), "Heuristics for Product-Line Design Using Conjoint Analysis," Management Science, 36(12), 1464-1478.

Kuhfeld, Warren F., Randall D. Tobias and Mark Garratt (1994), "Efficient Experimental Design with Marketing Applications,” Journal of Marketing Research, 31 (4), 545-557.

Lachaab Mohamed, Asim Ansari, Kamel Jedidi, and Abdelwahed Trabelsi (2006), "Modeling Preference Evolution in Discrete Choice Models: A Bayesian State-Space Approach,” Quantitative Marketing and Economics (4), 57-81.

Lee, Thomas Y. and Eric T. Bradlow (2007), “Automatic Construction of Conjoint Attributes and Levels From Online Customer Reviews,” working paper, The Wharton School, University of Pennsylvania.

Lenk, Peter J., Wayne S. DeSarbo, Paul E. Green and Martin R. Young (1996), "Hierarchical Bayes Conjoint Analysis: Recovery of Partworth Heterogeneity from Reduced Experimental Designs," Marketing Science, 15 (2), 173--91.

Liechty, John C., Duncan K. H. Fong and Wayne S. DeSarbo (2005), "Dynamic Models Incorporating Individual Heterogeneity: Utility Evolution in Conjoint Analysis,” Marketing Science, 24(2), 285-293.

Liechty, John, Rik Pieters and Michel Wedel (2003), "Global and local covert visual attention: Evidence from a Bayesian hidden Markov model,” Psychometrika, 68, 519-542.

Liechty, John, Venkatram Ramaswamy, and Steven H. Cohen (2001), “Choice Menus for Mass Customization: An Experimental Approach for Analyzing Customer Demand with an Application to a Web-Based Information Service,” Journal of Marketing Research, 38 (2), 183-196.

Louviere, Jordan J., Robert J. Meyer, David S. Bunch, Richard Carson, Benedict Dellaert, Michael Hanemann, David A. Hensher, and Julie Irwin (1999), “Combining Sources of Preference Data for Modeling Complex Decision Processes,” Marketing Letters, 10 (3), 187-204.

Luo, Lan., P. K. Kannan, Babak Besharati, and Shapour Azarm (2005), "Design of Robust New Products under Variability: Marketing Meets Design,” Journal of Product Innovation Management, 22, 177-192.

Luo, Lan, P.K. Kannan and Brian Ratchford (2007), "Incorporating subjective characteristics in product design and evaluations,” Journal of Marketing Research, forthcoming.

Marshall, Pablo and Eric T. Bradlow (2002) “A Unified Approach to Conjoint Analysis Models,” Journal of the American Statistical Association, 97 (459), 674-682.

McBride, Richard, and Fred S. Zufryden (1988), “An Integer Programming Approach to the Optimal Product Line Selection Problem,” Marketing Science, 7 (2), 126-140.

Michalek, Jeremy J., Fred. M. Feinberg and Panos Y. Papalambros (2005), "Linking Marketing and Engineering Product Design Decisions via Analytical Target Cascading,” Journal of Product Innovation Management, 22, 42-62.

Michalek, Jeremy J., Fred. M. Feinberg, Peter Ebbes, Feray Adigüzel and Panos Y. Papalambros (2007), “Optimal Feasible Product Line Design for Heterogeneous Markets,” working paper, Department of Mechanical Engineering, Carnegie-Mellon University.

Netzer, Oded, Rom Schrift and Olivier Toubia (2007), "Modeling and Exploiting Response Time in Conjoint Analysis,” working paper, Columbia Business School. 
Netzer, Oded and V. Srinivasan (2007) “Adaptive Self-Explication of Multi-Attribute Preferences,” working paper, Columbia Business School.

Otter Thomas, Greg M. Allenby and Trish van Zandt (2007), “An Integrated Model of Choice and Response Time with Applications to Conjoint Analysis” working paper, Ohio State University.

Park, Young Hoon, Min Ding and Vithala R. Rao (2007), "Eliciting Preference for Complex Products: A Web-Based Upgrading Method,” working paper, Cornell University.

Prelec, Dražen (1998), “The Probability Weighting Function,” Econometrica, 66 (3), 497-527

Prelec, Dražen (2001), “A Two-person Scoring Rule for Subjective Reports,” working Paper, Center for Innovation in Product Development, Cambridge, MA, Massachusetts Institute of Technology.

Rao, Vithala R and Joel H. Steckel (1991), “A Polarization Model for Describing Group Preferences,” Journal of Consumer Research, 18 (1), 108-118.

Rossi, Peter E. and Greg M. Allenby (2003), “Bayesian Statistics and Marketing,” Marketing Science, 22 (3), 304-328.

Saigal, Christopher, Ely Dahan and William Cumberland (2007), "Measuring Prostate Cancer Treatnment Preferences with Standard Gambles, Time Tradeoffs and Conjoint Analysis,” NIH Research Proposal.

Sandor, Zsolt and Michel Wedel (2001) "Designing Conjoint Choice Experiments Using Managers Prior Beliefs,” Journal of Marketing Research,.38, 430-444.

Sandor, Zsolt and Michel Wedel (2005), “Heterogeneous conjoint choice designs,” Journal of Marketing Research, 42, 210-218.

Sonnier, Garrett, Andrew Ainslie and Thomas Otter (2007) "Heterogeneity Distributions of Willingnessto-Pay in Choice Models," working paper. Available at SSRN: http://ssrn.com/abstract=928412.

Srebro, N., J. D. M. Rennie and T. Jaakkola (2005), “Maximum margin matrix factorization,” Advances In Neural Information Processing Systems, 17.

Srinivasan, V. (1988), “A Conjunctive-Compensatory Approach to the Self-Explication of Multiattributed Preferences,” Decision Sciences, 19 (Spring), 295-305.

Srinivasan, V., William S. Lovejoy and David Beach (1997), "Integrated Product Design for Marketability and Manufacturing,” Journal of Marketing Research, 34 (1), 154-163

Srinivasan, V., and Allan D. Shocker (1973a), "Linear Programming Techniques for Multidimensional Analysis of Preferences,” Psychometrika, 38 (3), 337-369.

Srinivasan, V. and Allen D. Shocker (1973b), "Estimating the Weights for Multiple Attributes in a Composite Criterion Using Pairwise Judgments,” Psychometrika, 38 (4), 473-493.

Su, Meng and Vithala R. Rao (2007), "Evolution in Willingness to Pay at Attribute Level and Its Impact on New Product Adoption: A Continuous Conjoint Analysis,” working paper, Cornell university.

Tanaka, Tomomi, Colin F. Camerer and Quang Nguyen (2007), "Risk and Time Preferences: Experimental and Household Survey Data from Vietnam,” working paper, California Institute of Technology.

Ter Hofstede, Frenkel, Youngchan Kim and Michel Wedel (2002), Bayesian prediction in hybrid conjoint analysis,” Journal of Marketing Research, 34 (2), 253-261,

Toubia, Olivier, Theodoros Evgeniou and John R. Hauser (2007), “Optimization-Based and MachineLearning Methods for Conjoint Analysis: Estimation and Question Design,” in Gustafsson, Anders, Andreas Herrmann, and Frank Huber (editors), "Conjoint Measurement: Methods and Applications (fourth edition),” Springer Verlag: Berlin.

Toubia, Olivier and John R. Hauser (2007), “On Managerially Efficient Experimental Designs,” Marketing Science, forthcoming.

Toubia, Olivier, John R. Hauser and Rosanna Garcia (2007), "Probabilistic Polyhedral Methods for Adaptive Choice-Based Conjoint Analysis: Theory and Application,” Marketing Science, forthcoming. 
Toubia, Olivier, John R. Hauser and Duncan Simester (2004), "Polyhedral Methods for Adaptive Choice Based Conjoint Analysis,” Journal of Marketing Research, 41 (1), 116-131.

Toubia, Olivier, Duncan Simester, John R. Hauser and Ely Dahan (2003), "Fast Polyhedral Conjoint Estimation,” Marketing Science, 22 (3), 274-303.

Tversky, Amos and Daniel Kahneman (1992), “Advances in prospect theory: Cumulative representation of uncertainty,” Journal of Risk and Uncertainty, 5 (4), 297-323.

Vadali, Srikant, John Liechty and Arvind Rangaswamy (2007) “Generalized Hierarchical Bayes Estimation for Polyhedral Conjoint Analysis,” Working Paper, Pennsylvania State University.

von Hippel, Eric and Ralph Katz (2002), “Shifting Innovation to Users via Toolkits,” Management Science, 48 (7), 821-833.

Wassenaar, Hank J., Wei Chen, Jie Cheng and Agus Sudjianto (2005), "Enhancing Discrete Choice Demand Modeling for Decision-Based Design,” ASME Journal of Mechanical Design, 127 (4), 514-523.

Wind, Jerry, Paul E., Green, Douglas Shifflet and Marsha Scarbrough (1989), “Courtyard by Marriott: Designing a Hotel Facility with Consumer-Based Marketing Models,” Interfaces, 19, 25-47.

Wittink, Dick R., and Philippe Cattin (1989), “Commercial Use of Conjoint Analysis: An Update,” Journal of Marketing 53 (3). 91-96.

Wittink, Dick R., Lakshman Krishnamurthi and David J. Reibstein. (1989). "The Effect of Differences in the Number of Attribute Levels on Conjoint Results,” Marketing Letters, 1, 113-123.

Yee, Michael, Ely Dahan, John R. Hauser and James Orlin (2007) “Greedoid-Based Noncompensatory Inference,” Marketing Science, forthcoming.

Ying, Yuanping, Fred M. Feinberg and Michel Wedel (2006), "Leveraging Missing Ratings to Improve Online Recommendation Systems,” Journal of Marketing Research, 43(3), 355-365. 